\title{
GERAÇÃO DE SPIN-OFFS TECNOLÓGICOS - UM ESTUDO MULTICASO
}

\section{TECHNOLOGY SPIN-OFFS GENERATION - A MULTICASE STUDY}

\author{
Jonas Mendes Constante*E-mail: jonasmendes@gmail.com \\ Nathalia Fiala*E-mail: nathaliafiala@gmail.com \\ Tales Andreassi* E-mail: tales.andreassi@fgv.br \\ *Escola de Administração de Empresas de São Paulo (EAESP/FGV), São Paulo, SP
}

\begin{abstract}
Resumo: O objetivo do estudo é compreender como pequenas e médias empresas podem inovar por meio de spin-offs tecnológicos, identificando motivações, influências e barreiras para realização deste fenômeno. A pesquisa classifica-se como qualitativa e exploratória, sendo analisados quatro casos de spin-offs tecnológicos no Estado de Santa Catarina. Os dados foram coletados a partir de observações em campo, dados históricos e entrevistas semiestruturadas. As principais motivações encontradas para geração de spin-offs foram: diversificação e complemento à cadeia de valor da empresa-mãe, e garantia de maior foco para uma tecnologia específica. Já a principal barreira encontrada foi a falta de capital. As iniciativas governamentais de apoio à criação de novas empresas, aliadas à cultura organizacional aberta ao empreendedorismo e investimentos em P\&D contribuíram para o desenvolvimento dos spin-offs analisados. Este trabalho contribui para o entendimento de que pequenas e médias empresas de base tecnológica são fonte de geração de spin-offs tecnológicos e podem beneficiar-se com a ocorrência deste processo.
\end{abstract}

Palavras-chave: Spin-Offs. Tecnologia. Inovação. Empreendedorismo Corporativo.

\begin{abstract}
The objective of this study is to understand how small businesses can innovate through the generation of technological spin-offs, identifying motivations, influences and barriers to achieving this phenomenon. Through a qualitative and exploratory study, we analyzed four cases of technological spin-offs in Santa Catarina State. We collected data through field observations, historical data and semi-structured interviews. The main reasons found for spin-offs creation were: diversification and to complement the value chain of the parent company and to ensure greater focus for a specific technology. The main barrier was lack of capital. Government initiatives to support the creation of new businesses, coupled with the organizational culture open to entrepreneurship and investment in R\&D, contributed to the development of spin-offs analyzed. This work contributes to the understanding that small and medium-sized technology-based companies are a source of technological spin-offs and can benefit from the occurrence of this process.
\end{abstract}

Keywords: Spin-Offs.Technology. Innovation. Corporate Entrepreneurship.

\section{INTRODUÇÃO}

Spin-off é o processo de geração de novas empresas a partir de organizações existentes, sejam elas empresas ou centros de pesquisa como universidades, laboratórios e institutos (CARAYANNIS et al., 1998). Um spin-off pode ocorrer quando um determinado colaborador decide sair da empresa para abrir

Revista Produção Online, Florianópolis, SC, v.14, n. 2, p. 617-647, abr./jun. 2014. 
seu próprio negócio com base nos conhecimentos adquiridos ao longo do tempo. Também é considerado spin-off uma situação em que a própria organização toma a decisão deliberada de abrir uma nova empresa, seja para fins de reestruturação ou exploração de novas oportunidades (LUC; FILLION, 2002).

Recentemente, com uma maior disseminação da importância da inovação e a adoção de modelos inovação mais abertos pelas empresas, o interesse no desenvolvimento de spin-offs tem aumentado. A inovação, entendida pelo Manual de Oslo (OECD, 2005) como a implementação de um novo ou aprimorado produto, processo, método mercadológico ou prática organizacional interna, organização de local de trabalho ou relações externas, pode ser classificada como inovação incremental e radical.

Para Freeman (1982), a inovação incremental é o tipo de inovação que introduz alterações nos produtos ou processos que não modificam a estrutura de produção, o que não acontece com as inovações radicais, que exigem uma reformulação nas estruturas produtivas. Para O'Connor e Demartino (2006), o grau de novidade ou impacto que as inovações radicais geram nos mercados exige que a empresa desenvolva competências específicas em tecnologia, mercado e em nível organizacional, gerando a "necessidade de mudança de toda ordem, como rotinas completamente novas, modificações pesadas nos normativos e no sistema de valores dos membros de uma organização" (LIMA; MENDES, 2003, p. 12).

Assim, neste contexto de mudança radical acompanhada pela exigência de fortes transformações, os spin-offs podem ser uma opção interessante para uma empresa investir em uma inovação radical, sem colocar em risco sua linha atual de produtos ou serviços, que acabam sendo aprimorados pela inovação incremental ou mesmo pelos processos de melhoria contínua.

A grande maioria dos estudos científicos publicados sobre spin-offs dizem respeito aos spin-offs acadêmicos, isto é, empresas que têm sua gênese nas universidades. Poucos são os estudos que se dedicam a estudar os spin-offs corporativos, em que as empresas têm sua origem dentro de outras organizações, bem como a relação entre empresa-mãe e empresa-filha, como apontam Semadeni e Cannella Jr. (2011).

Em relação a estudos brasileiros, não foram encontradas na base EBSCO 
nos últimos 10 anos publicações dedicadas aos spin-offs corporativos no Brasil, embora houvesse dois estudos sobre spin-offs acadêmicos (BOTELHO; ALMEIDA, 2010; COSTA; TORKOMIAN, 2011), razão pela qual o presente estudo tem um caráter inovador para a realidade brasileira.

O objetivo do estudo é compreender como pequenas e médias empresas podem inovar por meio de spin-offs tecnológicos. Como objetivos específicos, a pesquisa buscará identificar as motivações, barreiras e influências relacionadas à geração de spin-offs tecnológicos, bem como as formas de governança e de captura de valor por parte das empresas-mãe.

\section{REFERENCIAL TEÓRICO}

\subsection{Empreendedorismo corporativo}

A extensão do conceito de empreendedorismo para o ambiente corporativo foi realizada ao longo das últimas décadas por acadêmicos do tema. Seja por meio dos termos empreendedorismo corporativo, intraempreendedorismo ou ainda empreendedorismo interno, este campo de estudo se desenvolveu fortemente amparado, principalmente, pela intenção das organizações de compreender como fomentar inovações internas e estimular colaboradores a criarem novos produtos, processos e negócios. Segundo Lazzari, Bampi e Milan (2014), para uma empresa ter sucesso, é importante que ela seja capaz de criar e reter conhecimentos, o que exige um ambiente que estimule a inovação. O Quadro 1 apresenta algumas definições de empreendedorismo corporativo pelos principais estudiosos do tema. 
Quadro 1 - Definições de empreendedorismo corporativo

\begin{tabular}{|c|c|}
\hline \multicolumn{2}{|c|}{ Definiçōes de Empreendedorismo Corporativo } \\
\hline Autor(es) & \begin{tabular}{|c|} 
Definiçăo \\
\end{tabular} \\
\hline Burgelman (1983) & $\begin{array}{l}\text { "Empreendedorismo corporativo refere-se ao processo } \\
\text { pelo qual as empresas se envolvem na diversificaçăo } \\
\text { através de desenvolvimentos internos. Tal diversificaçăo } \\
\text { requer combinaçð̋es de novos recursos para ampliar a } \\
\text { açăo da empresa a outras áreas, ou mesmo às suas } \\
\text { atuais áreas, de atuaçăo, correspondendo ao conjunto } \\
\text { de oportunidades que a empresa está buscando." }\end{array}$ \\
\hline Chung e Gibbons (1997) & $\begin{array}{l}\text { "Empreendedorismo corporativo é um processo de } \\
\text { organizaçăo que visa a transformação de idéias } \\
\text { individuais em açőes coletivas através do gerenciamento } \\
\text { das incertezas." }\end{array}$ \\
\hline Covin e Slevin (1991) & $\begin{array}{l}\text { "Empreendedorismo corporativo envolve a extensão do } \\
\text { dominio de competência da empresa e corresponde a } \\
\text { um conjunto de oportunidades através da combinação de } \\
\text { novos recursos gerados internamente na organizaçăo." }\end{array}$ \\
\hline Guth e Ginsberg (1990) & $\begin{array}{l}\text { "Empreendedorismo corporativo envolve dois tipos de } \\
\text { fenómenos e de processos que os cercam: } \\
\text { 1) o nascimento de novos negócios dentro de } \\
\text { organizaçóes existentes, isto é, inovaçóes internas; e } \\
\text { 2) a transformaçăo das organizaç̋̄es através da } \\
\text { renovaçăo das áreas-chave sobre as quais a empresa é } \\
\text { sustentada, ou seja, renovaçăo estratégica." }\end{array}$ \\
\hline $\begin{array}{l}\text { Jennings e Lumpkin } \\
\text { (1989) }\end{array}$ & $\begin{array}{l}\text { "Empreendedorismo corporativo é definido como a } \\
\text { extensâo do desenvolvimento de novos produtos e/ou } \\
\text { novos mercados. Uma organização é empreendedora se } \\
\text { ela desenvolve um número maior que a média de novos } \\
\text { produtos ou mercados." }\end{array}$ \\
\hline Schendel (1990) & $\begin{array}{l}\text { "Empreendedorismo corporativo envolve a noçáo de } \\
\text { nascimento de um novo negócio dentro de um negócio } \\
\text { em atividade e, ainda, a transformaçăo de um negócio } \\
\text { estagnado, que necessita ser reformulado e renascer." }\end{array}$ \\
\hline $\begin{array}{l}\text { Spann, Adams e } \\
\text { Wortman (1988) }\end{array}$ & $\begin{array}{l}\text { "Empreendedorismo corporativo é o estabelecimento de } \\
\text { uma organizaçăo separada (geralmente na forma de } \\
\text { uma nova area, unidade de negócios estratégica, } \\
\text { divisăo, subsidiária) para a introduçăo de um novo } \\
\text { produto ou serviço, ou criando um novo mercado ou, } \\
\text { ainda, utilizando uma nova tecnologia." }\end{array}$ \\
\hline Zahra (1991) & $\begin{array}{l}\text { "Empreendedorismo corporativo refere-se ao processo } \\
\text { de criar novos negócios em organizaçós existentes } \\
\text { para aumentar a lucratividade e fortalecer sua posiçâo } \\
\text { competitiva ou renovar estrategicamente o negócio } \\
\text { existente" }\end{array}$ \\
\hline
\end{tabular}

Fonte: Adaptado de Dornelas (2003)

As tipologias para o empreendedorismo corporativo também não são consenso na bibliografia, mas ao menos três linhas de escolas de pensamento são presentes: intraempreendedorismo, transformação empreendedora e corporate venturing. Cada uma dessas escolas estuda o empreendedorismo corporativo sob óticas distintas.

O termo intraempreendedorismo, introduzido por Pinchot (1985), tem como foco o indivíduo empreendedor dentro da organização e como estimular suas ações.

Revista Produção Online, Florianópolis, SC, v.14, n. 2, p. 617-647, abr./jun. 2014. 
Birkinshaw (1997) investigou como as estruturas organizacionais podem inibir o empreendedorismo e o comportamento dos empreendedores corporativos de sucesso.

A transformação empreendedora ou renovação estratégica é abordada nos trabalhos de Peters e Waterman (1982) e Kanter (1989), centrando-se no fato de a organização poder efetuar adaptações em seus sistemas e em sua cultura para favorecer que ações empreendedoras partam de seus colaboradores. O termo transformação ou renovação justifica-se em virtude da alta competição com as quais grandes empresas se defrontam, fazendo com que a geração de inovações seja uma prerrogativa para manterem-se competitivas.

Baseado nos trabalhos de Burgelman (1983) e Druker (1985) e mais recentemente Chesbrough (2003) e Christensen e Raynor (2003), uma escola de pensamento que vem ganhando destaque é a do corporate venturing, que abrange o estímulo e gerenciamento de novos negócios internos e externos à organização. Essa escola centra-se no estudo do alinhamento dos novos negócios com estratégia corporativa da organização. Em virtude de práticas de corporate venturing estarem intimamente ligadas à geração de spin-offs, tal tópico será abordado com maiores detalhes a seguir.

\subsubsection{Corporate Venturing}

Segundo Von Hippel (1988, p. 163), corporate venturing "é uma atividade que busca gerar novos negócios para a corporação por meio do estabelecimento de empreendimentos externos ou internos".

Guth e Ginsberg (1990, p. 10) reforçam a perspectiva do negócio inovador na definição do conceito. Segundo esses autores, corporate venturing é o "surgimento de novos negócios dentro de uma organização existente e que transforme a organização a partir da renovação das premissas sobre as quais essa organização é construída".

O estudo de corporate venturing é encontrado na literatura em dois subtipos: o corporate venturing interno e o corporate venturing externo (SHARMA; CHRISMAN, 1999). O corporate venturing interno corresponde basicamente ao 
desenvolvimento de novas unidades e departamentos corporativos. Já o corporate venturing externo trata da criação de novos negócios externos à estrutura original da empresa. Spin-offs, fusões, joint-ventures são classificados como forma de corporate venturing externo.

A adoção da prática de corporate venturing pelas organizações tem demonstrado seguir movimentos cíclicos, afetada fortemente pelo estado da economia mundial. Atualmente, busca-se nos programas de corporate venturing uma gestão mais eficaz, que maximize os resultados aproveitando as oportunidades existentes para a organização, tanto financeiramente como estrategicamente.

\subsection{Spin-offs}

Spin-off é o processo de criação de uma nova organização a partir de uma outra já estabelecida. Este mecanismo pode ser utilizado para tornar uma organização mais enxuta, se desfazendo de departamentos deficitários ou periféricos ao negócio principal, podendo se tornar lucrativos se explorados por uma nova empresa. Podem ainda tomar forma como estratégia de exploração de oportunidades, especialmente oportunidades de nicho, onde a estrutura original da empresa-mãe não tem condições de atender, seja pela sua ineficiência operacional gerada pela burocracia interna de uma grande organização, seja por sua cultura interna como o perfil de seus colaboradores e gestores.

Ao realizar-se uma revisão da literatura sobre o conceito de spin-off e suas tipologias é possível encontrar inúmeras divergências, principalmente relacionadas à falta de uniformidade entre os conceitos empregados. Como exemplo podem-se citar estudos relativos ao número de spin-offs ocorridos ao redor do Massachusetts Institute of Technology (MIT) ao longo dos anos. Roberts e Malone (1996) chegaram à taxa de 6,4 spin-offs anuais durante os últimos 30 anos. Já Bray e Lee (2000) estimaram o número em torno de 25 durante os últimos 20 anos, enquanto Carayannis et al. (1998) chegaram à taxa de 140 ao ano. Essa falta de uniformidade entre os conceitos pode causar grandes riscos a pesquisas futuras, uma vez que os pesquisadores utilizam o mesmo conceito para descrever situações distintas (PIRNAY; SURLEMONT; NLEMVO, 2003), dificultando, assim, o avanço 
das pesquisas sobre o tema.

No estudo dos tipos de spin-offs, as variáveis que têm maior peso na literatura são o tipo de organização que gerou a nova empresa e o objetivo da decisão de geração do spin-off. Com relação ao tipo de organização geradora, Tübke (2004), apoiando-se na definição de Shane (2004), propõe uma tipologia com dois tipos de spin-offs: corporativos (oriundos de empresas) e institucionais (oriundos de universidades e instituições públicas e privadas). Já Dahlstrand (1997a) apresenta uma tipologia com três tipos: a) spin-offs corporativos; b) spinoffs universitários e c) spin-offs institucionais.

A busca pela inovação por meio de investimentos em P\&D e o estabelecimento de programas de corporate venturing tendem a resultar na geração de spin-offs conhecidos na literatura como spin-offs corporativos de cunho tecnológico ou spin-offs corporativos tecnológicos (SCTs). Muegge (2004) definiu como empresas oriundas de SCTs aquelas que atendem aos seguintes requisitos: a) nova empresa foi fundada com a participação de colaboradores da empresamãe; b) a nova empresa visa à comercialização de tecnologia desenvolvida ou possuída pela empresa-mãe; c) a nova empresa foi ou é suportada pela empresamãe por meio do acesso a clientes, fornecedores, capital, propriedade intelectual ou outros recursos. Os spin-offs corporativos tecnológicos, segundo a definição de Muegge (2004), serão o foco do presente estudo.

\subsubsection{Fatores relevantes na geração e desenvolvimento de SCTs}

A seguir são apresentados os principais fatores apontados pela literatura no processo de geração e desenvolvimento de SCTs.

Ambiente externo: Fatores externos incluem aspectos sobre os quais os responsáveis pela iniciativa de spin-off não possuem controle, como condições econômicas e regionais e do mercado em que está inserido. Luc e Fillion (2002) destacam que uma política industrial favorável a spin-off, programas de apoio governamental, recursos e entidades regionais de promoção ao empreendedorismo e inovação nas empresas, e regiões baseadas em clusters empresariais são alguns dos elementos importantes externos à organização que facilitam a geração 
de SCT. Regiões com alta taxa de spin-off, como o Vale do Silício nos Estados Unidos, apresentam as características mencionadas acima.

Motivação dos empreendedores: Empreendedores fundadores de empresas geradas por spin-offs são motivados pelos mesmos fatores dos empreendedores tradicionais (COOPER, 1971; BHIDÉ, 2000), como geração de riqueza, reconhecimento na sociedade, independência e poder. Garvin (1983) afirma que colaboradores que deixam seus antigos empregos para assumir posições na nova empresa relatam insatisfação na empresa-mãe em virtude de uma ideia rejeitada ou não continuada.

Outra motivação para SCT é a possibilidade do patrocínio do seu próprio negócio pela empresa-mãe, o que favorece ao colaborador vislumbrar maiores chances para o novo negócio, como afirma Teece (1998).

Motivação dos Investidores: Segundo Chesbrough e Rosenbloom (2002), investidores influenciam nas estratégias corporativas dos spin-offs nos quais participam. Cabe destacar que em grande parte dos casos de spin-offs corporativos é a empresa-mãe quem assume o papel de investidora.

Motivação da empresa-mãe: Christensen (1997) argumenta que um dos motivos é a possibilidade de desenvolver uma tecnologia disruptiva - ou seja, que rompe com a anterior - que teria sérios problemas para ser desenvolvida internamente. Já Anslinger et al. (1997) comentam sobre a possibilidade de a empresa reter participação acionária em um novo negócio que internamente não teria ambiente para receber aporte de recursos. Outras motivações seriam o objetivo de desenvolver o espírito empreendedor dentro da organização - retendo e atraindo talentos (Hellmann, 2007) - e de obter acesso a investidores de risco externos (DAHLSTRAND, 1997b).

Fatores tecnológicos: Segundo Shane (2004), a propensão de uma inovação ser explorada via criação de spin-off varia de acordo com a tecnologia em questão. Quanto mais inovadora e disruptiva for uma tecnologia, maiores serão as chances de um processo de spin-off ocorrer. Lowe (1993) também suporta o argumento de Shane (2004) ao afirmar que spin-offs corporativos tecnológicos ocorrem em indústrias emergentes, onde as trajetórias tecnológicas ainda estão sendo desenvolvidas e as inovações são radicais. 
Políticas públicas: Spin-offs de base tecnológica têm demonstrado ser um ótimo instrumento para o desenvolvimento e aumento da competitividade em algumas regiões (Organização para a Cooperação Econômica e Desenvolvimento [OECD], 2005. p.3). Conforme argumenta Tübke (2004), o Vale do Silício deve seu crescimento e importância em grande parte ao surgimento dos spin-offs da Farchild Semicondutores na década de 70, assim como o cluster finlandês de telecomunicações aos spin-offs da Nokia. Moncada-Paternò-Castello et al. (1999) citam algumas medidas públicas que podem ser adotadas para o estímulo à geração de spin-offs de base tecnológica: ações que favoreçam a publicidade do processo de spin-off de modo que esta cultura seja disseminada, e editais públicos para fomento de recursos a pesquisadores e colaboradores que, em parceria com seus atuais empregadores, tenham interesse em iniciar um nova empresa de cunho tecnológico.

\section{METODOLOGIA DE PESQUISA}

O enfoque que um determinado estudo pode assumir vai depender de seu objetivo específico, podendo ser exploratório, descritivo ou explicativo (GIL, 2002). presente estudo tem um caráter exploratório, uma vez que este tipo de pesquisa objetiva uma maior familiarização com o problema, sendo sua característica básica a não formulação de hipóteses (Selltiz et al., 1975). Ainda que esse tipo de estudo agregue elementos de estudos descritivos (descrição de uma série de exemplos, eventos e situações dentro de uma área específica de interesse), não apresenta sua característica principal, que é a clara formulação do que ou quem deve ser medido, bem como de técnicas para medidas válidas e precisas (Selltiz et al., 1975).

$\mathrm{O}$ trabalho adotou o método qualitativo de pesquisa. Este tipo de pesquisa parte de focos de interesse ou questões amplas, que vão se definindo no decorrer do estudo. O objetivo não é medir ou enumerar eventos, nem utilizar instrumentos estatísticos para análise dos dados (GODOY, 1995).

A técnica empregada para o desenvolvimento da pesquisa foi o estudo de caso. A característica que distingue o estudo de casos de outras estratégias de pesquisa, segundo Yin (1981), é que nele tenta-se examinar um fenômeno recente 
em seu contexto real, especialmente quando os limites entre o fenômeno do passado e o contexto não são evidentes. A adoção da metodologia de estudo de casos e da recomendação do processo sugerida por Eisenhardt (1989) foi feita em virtude de os trabalhos acadêmicos sobre spin-offs tecnológicos corporativos serem um campo ainda pouco explorado dentro da área de estratégia e empreendedorismo, além de o número de incidências deste fenômeno ser reduzido no Brasil.

Para Eisenhardt (1989), é importante ter em mente que, nessa metodologia, o início do processo seja o mais próximo possível da ausência de hipóteses a serem testadas, evitando o pensamento prévio de relações entre variáveis e teorias. É importante apenas ter o foco nos objetivos de pesquisa e nos problemas para os quais se desejam buscar soluções. Buscou-se identificar casos de spin-offs corporativos que atendessem as seguintes características, seguindo a definição de Muegge (2004): a) a empresa-filha foi fundada com a participação de colaboradores da empresa-mãe; b) a empresa-filha visa à comercialização de tecnologia desenvolvida ou possuída pela empresa-mãe; c) a empresa-filha foi ou é suportada pela empresa-mãe.

A pesquisa foi realizada com spin-offs gerados nos últimos cinco anos por pequenas e médias empresas de base tecnológica situadas em Santa Catarina. Optou-se por limitar os casos dentro desta localidade de modo a obter empresas expostas a um mesmo ambiente externo. Florianópolis, capital de Santa Catarina, destaca-se por ser um reconhecido polo de inovação, sendo sua economia fortemente baseada na indústria de tecnologia da informação. A cidade apresenta quatro incubadoras e um parque tecnológico de grande porte, uma quantia considerável de estruturas para suporte ao empreendedorismo tecnológico quando comparado a sua população de aproximadamente 480.000 habitantes. Quatro casos atendiam os pré-requisitos da pesquisa e foram selecionados:

a) Caso 1: A Talk\&Write é uma pequena empresa de desenvolvimento de soluções para colaboração online situada em Florianópolis (SC). A empresa gerou seu primeiro spin-off em 2009, a Tawsoft, cujo foco é o mercado de educação, fornecendo uma tecnologia proprietária de lousas digitais.

b) Caso 2: A llog é uma pequena empresa de desenvolvimento de 
software, atuando como prestadora de serviços e também com soluções próprias, principalmente no segmento de educação corporativa e e-learning. Em 2008 a empresa decidiu separar a sua divisão de serviços e a de produtos, dando maior atenção a esta última, com a criação da Sensus.

c) Caso 3: A CERTI é uma instituição de médio porte que possui 26 anos no desenvolvimento de soluções inovadoras para os mais diversos setores. A Sábia, empresa spin-off, é uma das companhias incubadas no Sapiens Parque, polo de inovação idealizado pela Certi, no Norte da Ilha de Santa Catarina. Os focos da empresa são conquistar mercado para o eCog, um computador multitouch que facilita o aprendizado e o trabalho em grupo, e desenvolver sistemas para ampliar o uso do seu produto único.

d) Caso 4: A Automatisa é uma empresa que desenvolve e comercializa máquinas para corte e gravação a laser. Após a percepção de outras necessidades nos mercados onde atua, a Automatisa expandiu em 2009 seus negócios, com a criação da Alkimat, empresa spin-off que atua na fabricação e comercialização de aditivos utilizados para marcação e gravação a laser. Os produtos já são exportados para dezenas de países.

O método de coleta de dados utilizado foi o de entrevistas semiestruturadas, observações em campo e dados históricos. Um roteiro para as entrevistas semiestruturadas foi elaborado visando obter informações que caracterizassem a empresa-mãe no momento do spin-off, no processo de spin-off, e a situação atual da nova empresa e empresa-mãe no momento da entrevista. Para tanto, o roteiro abordou quatro aspectos principais: os fatores que estimularam a geração dos spinoffs, as barreiras encontradas, a estrutura organizacional e governança das empresas-filhas, e as formas de captura, pela empresa-mãe, do valor gerado pelo spin-off. Estes quatro aspectos acabaram sendo adotados como as categorias de análise.

$\mathrm{Na}$ fase da coleta de dados, foram anotadas quaisquer impressões de uma forma proativa. Em outras palavras, houve a observação, anotação, interação com os envolvidos explorando os pequenos temas e novamente marcando as novas observações. Os entrevistados foram selecionados devido à sua posição na empresa e ao envolvimento no processo de spin-off. Em cada empresa-mãe foram 
entrevistados dois executivos da área de inovação ou ligados à área de novos negócios e que tenham tido envolvimento com o processo de spin-off. Além disso, entrevistou-se também os empreendedores/ sócios da nova empresa criada pelo spin-off.

Desta forma, foram entrevistados os seguintes atores: Talk\&Write e Tawsoft, dois sócios da empresa-mãe e dois sócios da empresa-filha; llog e Sensus, três sócios da empresa-mãe e dois sócios da empresa-filha; Certi e Sábia Experience, um diretor da empresa-mãe e um sócio da empresa-filha; Automatisa Sistemas e Alkimat Tecnologia, um ex-sócio da empresa-mãe e dois sócios da empresa-filha.

Ressalta-se que determinados entrevistados, por terem participação tanto na empresa-mãe quanto na empresa-filha, foram conduzidos de modo a obter suas visões para as duas organizações. As entrevistas foram todas presenciais, com aplicação do roteiro semiestruturado. Cada entrevista foi gravada e teve duração de aproximadamente 40 minutos. Em determinados casos, houve a necessidade de troca de e-mails posteriores para complementar as informações.

A análise dos dados obtidos nas entrevistas foi realizada por meio da técnica da análise de conteúdo. Para Bardin (2010), análise de conteúdo é um conjunto de técnicas de análise que visa obter, através de procedimentos sistemáticos, indicadores - quantitativos ou não - que permitam a inferência de conhecimentos por meio das mensagens (neste caso, as entrevistas). Godoy (1995) afirma que a análise de conteúdo é um "instrumento metodológico que pode ser aplicado a discursos diversos e a todas as formas de comunicação, seja qual for a natureza de seu suporte" (GODOY, 1995, p. 23). A técnica de análise de conteúdo parte do pressuposto de que, por trás do discurso aparente, há um sentido escondido a ser desvendado. O esforço do analista é duplo: ele deve tentar entender o sentido da comunicação como um receptor normal, além de desviar o olhar para buscar outros significados, outras mensagens que podem ser enxergadas por meio da mensagem original.

Para a análise de conteúdo, foram definidas as quatro categorias de análise já descritas anteriormente, as quais são entendidas como rubricas ou classes que reúnem um grupo de elementos sob um título genérico, agrupamento esse que se deu em razão dos caracteres comuns desses elementos (BARDIN, 2010). 
Em relação à confiabilidade da pesquisa, ou seja, processos que garantam que, ao se repetir a pesquisa, os mesmos resultados serão obtidos, Yin (2001) sugere que o pesquisador desenvolva um protocolo de pesquisa, o qual foi adotado neste trabalho. Desta forma, todos os procedimentos de pesquisa (roteiro, pré-teste, contato com empresas participantes, agendamento, condução e transcrição das entrevistas etc.) foram identificados e anotados para garantir a uniformidade na condução do estudo.

Com relação à validade, Yin (2001) aponta que os resultados de um estudo de caso devem possuir validade de constructo, validade externa e validade interna. A validade de constructo foi obtida pela definição operacional dos conceitos estudados, relacionados no referencial teórico, bem como pela utilização de múltiplas fontes de evidências na condução dos casos. A validade externa, ou seja, em que medida os resultados podem ser generalizados, é obtida por meio da lógica de replicação, dado que foram realizados quatro estudos de caso. Por fim, a validade interna se aplica apenas aos estudos explanatórios e não nos que tem caráter exploratório-descritivo, como é o caso desta pesquisa.

\section{RESULTADOS}

Os resultados serão apresentados de forma agrupada, segundo as quatro categorias de análise descritas no tópico anterior.

\subsection{Fatores que estimulam a geração de spin-offs}

Nos casos analisados, podem-se agrupar os principais fatores de estímulo identificados em três blocos, a saber:

a) ambiente com investimento em pesquisa e desenvolvimento e cultura aberta ao empreendedorismo corporativo

Este primeiro fator foi observado in loco em todos os casos e também apontado pelos entrevistados. A Talk\&Write apresenta um ambiente com forte estímulo à criação de inovações e novos negócios, talvez por ser uma empresa de pequeno porte e ter como sócio majoritário um ex-pesquisador universitário. A 
empresa também possui uma área de P\&D. Na llog, os investimentos realizados buscando o desenvolvimento de novos produtos demonstram a preocupação da empresa com P\&D.

$\mathrm{Na}$ CERTI, os investimentos em P\&D são constantes e a organização é estruturada com base em seus projetos de pesquisa e desenvolvimento, contando com programas formais de empreendedorismo corporativo. A respeito do relacionamento entre sócios e colaboradores, ao ser perguntado sobre apoio à cultura empreendedora dentro da empresa, o atual sócio da empresa-filha, respondeu: "Na cultura de todos isso estava estabelecido e declarado. (...) A casa foi organizada por plataformas de produtos com o objetivo de gerar spin-offs."

$\mathrm{Na}$ Automatisa, existe um departamento de pesquisa e desenvolvimento e, apesar de não haver programas formais de apoio ao empreendedorismo corporativo, a abertura de oportunidades e acessibilidade das informações entre os sócios e colaboradores permitiam o empreendedorismo corporativo, como destaca um ex-sócio da empresa-mãe e atual sócio da empresa-filha: “...na minha história de empresa eu sempre fui atrás de um modelo de empresa diferente. Na cabeça eu sempre tinha ideias de trazer pra dentro da empresa e participar e até dentro da massa societária, vender para os próprios funcionários-chave dentro do negócio. $(\ldots)^{\prime \prime}$

Diante destas observações chegou-se à primeira proposição da pesquisa:

Proposição 1: Pequenas e médias empresas brasileiras de base tecnológica que realizam investimentos em P\&D e possuem cultura aberta ao empreendedorismo corporativo são um local fértil para a geração de spin-offs tecnológicos.

Esta proposição vai ao encontro de alguns autores que argumentam que as pequenas empresas constituem-se um ambiente mais propício para o surgimento e desenvolvimento de inovações, em virtude de não sofrerem comumente dos problemas enfrentados pelas grandes empresas, com rotinas estabelecidas (NELSON; WINTER, 1982), e dificuldade cognitiva de seus gestores em perceberem outros mercados de atuação. (CHESBROUGH; ROSENBLOOM, 2002). Por parte do colaborador envolvido no processo de spin-off, a possibilidade de patrocínio do seu próprio negócio pela empresa-mãe o faz vislumbrar maiores 
chances para o novo negócio (TEECE, 1998).

A própria natureza das empresas de base tecnológica, orientadas a desenvolver produtos com forte presença de capital intelectual, tende a ser um fator estimulador para o surgimento de inovações. Lowe (1993) e Shane (2004) afirmam que spin-offs corporativos tecnológicos ocorrem em maior proporção em indústrias emergentes, onde as trajetórias tecnológicas ainda estão sendo desenvolvidas e as inovações são radicais.

b) definição estratégica da empresa-mãe

O segundo fator apresentado como de estímulo à geração de spin-offs é a decisão estratégica da empresa-mãe, porém com objetivos distintos. No caso 1 , o foco principal do sócio majoritário da empresa-mãe era dar maior visibilidade a uma inovação radical, facilitar a organização administrativa em torno deste produto e atrair investidores, conforme comentou o mesmo:

\footnotetext{
Foi levada em consideração a existência de um outro produto. Por isso, por uma questão também de organização e para separar as coisas, acreditouse que, com o surgimento da nova empresa, o acréscimo de um produto (hardware), a empresa seria mais atrativa, fazendo com que fosse mais fácil de ser comercializado e de receber aporte do investidor.
}

Já o spin-off do caso 2 surgiu para facilitar a organização entre os departamentos de serviços e os produtos da empresa-mãe, garantindo maior visibilidade a estes. Para ilustrar, segue o comentário de um dos entrevistados: "A criação da Sensus a partir da llog deu-se pela necessidade em focar no produto e não simplesmente no serviço. Assim, toda a gestão da nova empresa foi moldada para o desenvolvimento do produto".

No caso 3, a empresa-mãe CERTI "buscava receita de outros mercados", segundo um dos entrevistados.

No caso 4, referente à Alkimat, empresa-filha da Automatisa, fica claro que o spin-off nasceu para completar a cadeia de valor da empresa-mãe no comentário de um dos sócios: "Nós trabalhamos com a linha de produtos consumíveis para alimentar as máquinas fabricadas pela empresa-mãe". Diante da análise dos casos estudados, formula-se a seguinte proposição:

Proposição 2: As principais motivações para a geração de spin-offs corporativos tecnológicos em pequenas e médias empresas brasileiras de base Revista Produção Online, Florianópolis, SC, v.14, n. 2, p. 617-647, abr./jun. 2014. 
tecnológica são: a) estratégia de diversificação da empresa-mãe; b) garantia de maior foco a uma tecnologia específica que dentro da empresa-mãe não seria possível; c) completar a cadeia de valor da empresa-mãe.

A proposição está em linha com o que a literatura apresenta sobre o tema. Christensen (1997) argumenta que uma das motivações é a possibilidade de desenvolver uma tecnologia que teria sérios problemas de ser desenvolvida internamente. Anslinger et al. (1997) argumenta que a opção por spin-off seria uma forma de a organização poder criar atenção para o novo produto. Atrair a atenção de investidores de risco à tecnologia foi um dos motivos principais para a realização do spin-off na pesquisa desenvolvida por Dahlstrand (1997a). Conforme citado por Parhankangas e Arenius (2003) e Chesbrough (2003), quando um produto ou tecnologia pode ser importante para a empresa-mãe em um momento futuro, o spin-off pode ser uma boa opção pois a empresa-mãe retém participação no desenvolvimento da tecnologia ou produto da empresa-filha.

c) programas governamentais de apoio à criação de novas empresas inovadoras

O terceiro fator de estímulo e desenvolvimento dos spin-offs é a existência de programas governamentais de apoio à criação de novos negócios inovadores. $O$ caso belga, descrito por Bruno, Netto e Bruno (2011) é um exemplo de programa governamental aplicado à inovação empresarial. No Brasil, a FINEP (Financiadora de Estudos e Projetos), por meio do programa Primeira Empresa Inovadora PRIME, está contribuindo para o desenvolvimento de todas as empresas-filhas analisadas neste trabalho.

O principal valor agregado observado pelos empreendedores é o capital disponibilizado e a possibilidade de contratação de consultorias especializadas e colaboradores para o negócio. Vale ressaltar que, por não contarem com um grande aporte de capital de recursos das empresas-mãe, programas governamentais deste tipo têm grande influência sobre spin-offs destas pequenas e médias empresas. Esta influência gerou a terceira proposição deste trabalho:

Proposição 3: Programas governamentais de apoio à criação de novas empresas favorecem a geração e o desenvolvimento de spin-offs por meio do capital financeiro disponibilizado e consultorias especializadas contratadas. 


\subsection{Barreiras do processo de geração de spin-offs}

Não foram encontrados, durante as entrevistas e observações dos casos analisados, muitos itens significativos que possam ser destacados como barreiras do processo de geração de spin-offs. Porém, em virtude dos casos tratarem de spin-offs oriundos de pequenas e médias empresas, pode ser observado que a barreira principal para geração destes neste contexto é a dificuldade em obter capital para o desenvolvimento inicial da empresa-filha. Alguns comentários dos sócios das empresas-filhas nas entrevistas corroboram para este entendimento: "Acesso ao capital é um problema porque é uma nova empresa e a linha de credito é limitada" e "Acesso ao capital sempre foi um problema. O que acontece é que a gente tem que andar numa marcha mais lenta".

A empresa-mãe e os sócios da mesma caracterizam-se como os principais financiadores das empresas-filhas analisadas. A maioria dos entrevistados argumenta que a existência de linhas de fomento para geração de spin-offs corporativos ou créditos mais atraentes nos bancos comerciais para pequenas e médias empresas de tecnologia seria um facilitador ao processo.

Diante do exposto chega-se a seguinte proposição:

Proposição 4: Nas pequenas empresas brasileiras de base tecnológica, o acesso ao capital é uma barreira para o desenvolvimento do spin-off em virtude deste depender sensivelmente do aporte de capital pelos sócios da empresa-mãe.

Em mercados mais desenvolvidos, como o norte-americano, a presença de capital de risco é abundante, e este tipo de financiamento tem tido uma grande função dentro da cadeia de geração e desenvolvimento de empresas de base tecnológica. Nos casos analisados por Muegge (2004) e Chesbrough (2003), grande parte das empresas-filhas recebeu aporte de investidores no momento do nascimento ou ao longo do desenvolvimento dos seus negócios. No Brasil, no entanto, o mercado de capital de risco ainda está se desenvolvendo e tem contado com o esforço de diversas entidades públicas em incentivá-lo, além do interesse crescente de fundos privados (Miziara e Carvalho, 2008).

$\mathrm{Na}$ maioria dos casos analisados neste estudo, o aporte de recursos pelos próprios sócios da empresa-mãe foi fundamental para a abertura e desenvolvimento 
inicial da empresa-filha. Isto ocorreu em virtude da limitada quantidade de recursos disponíveis para investimento por parte da empresa-mãe, pequenas e médias organizações. Como pontuado por La Rovere (2001) e Andrade Jr. (2012), este porte de empresa no Brasil é o que acaba tendo maior dificuldade de captar recursos no mercado. As empresas de base tecnológica, em particular, são as que mais necessitam de financiamento externo, pois precisam suportar seus negócios muitas vezes sem gerar receita por conta do modelo de negócio que criaram ou das novas tecnologias que estão desenvolvendo. Vale ressaltar, no entanto, que embora o apoio da empresa-mãe seja fundamental no início das atividades da empresa-filha, um excesso de controle da empresa-mãe acaba impedindo que a nova empresa se adapte ao mercado e se estabeleça como uma entidade independente, impactando negativamente em seu desempenho no longo prazo (SEMADENI; CANNELLA, 2011).

\subsection{Estrutura organizacional e governança das empresas-filhas}

O primeiro item relevante a ser destacado das observações obtidas em relação à estrutura e governança das empresas-filhas diz respeito à incubação e desenvolvimento inicial da ideia da criação da empresa até seu efetivo nascimento. Em todos os casos analisados, a incubação da nova empresa ocorreu dentro da empresa-mãe.

O principal motivo que levou estas empresas-mãe a optarem por incubar internamente a nova empresa parece ter sido a estreita relação entre elas nos casos de spin- offs analisados. Os relatos dos entrevistados ajudam a suportar este argumento: "A incubação aconteceu no suporte de negócios, suporte de infraestrutura, financeiro, comercial, suporte de negócios. Ligação bem estreita entre as empresas". Outro comentário foi: "Começou-se a criar dentro do espaço daquela empresa um grupo, um capital intelectual que começava a explorar aplicações e usos possíveis para lidar com as máquinas a laser". Outro entrevistado afirma que "aí surgiu a ideia de que aqueles pesquisadores que atuavam nessa plataforma seriam desafiados a se tornarem empreendedores". Outro fato que contribuiu para este tipo de incubação foi à carência de recursos financeiros, por 
parte dos atores envolvidos no processo, para suportar os custos associados à abertura e desenvolvimento de um novo negócio ainda em fase pré-operacional, sem geração de receita própria.

Foi observado também o fato de os spin-offs analisados não serem regidos por contratos prevendo a separação entre empresa-mãe e empresa-filha. Além disso, as empresas-filhas estudadas não sofreram ou sofrem restrições formais impostas por suas empresas-mãe. Isto também pode ser explicado, em parte, pelo forte vínculo entre empresa-mãe e empresa-filha nos casos analisados, como destacado pelos entrevistados nestes comentários: "infraestrutura como o servidor, data center, a empresa-filha sempre utilizou da empresa-mãe. Sempre houve essa relação muito próxima." e "não há divisão clara entre empresa-mãe e nova empresa. Há intenso vínculo entre a empresa-mãe e nova empresa." Os aspectos apresentados conduziram o desenvolvimento da seguinte proposição:

Proposição 5: Em pequenas e médias empresas brasileiras de base tecnológica, a estreita relação entre o spin-off e os interesses da empresa-mãe favorecem a incubação interna do novo negócio.

Como relatado por Richards (2001), a incubação ocorre internamente por parte da empresa-mãe visando garantir maior sucesso do novo negócio e mitigar possíveis riscos à reputação da mesma. Esta pesquisa sugere também outro fator associado à ligação entre a empresa-mãe e empresa-filha: em todos os casos analisados, essa relação era extremamente forte, o que favoreceu à empresamãe adotar a estratégia de incubar internamente o novo negócio.

$\mathrm{Na}$ avaliação do poder e tomada de decisões dentro das empresas-filhas, constatou-se em dois dos casos analisados um controle total por parte dos sócios da empresa-mãe. Os dois casos ocorreram nas pequenas empresas, Talk\&Write e llog. Nestes casos, o controle ocorre em virtude dos sócios da empresa-filha também serem os mesmos sócios da empresa-mãe.

Nos dois casos de spin-offs oriundos de médias empresas, foi observada uma maior participação dos fundadores da empresa-filha nas decisões estratégicas do negócio. No caso da CERTI, são os ex-colaboradores da empresa que comandam a empresa-filha. No caso da Automatisa, quem controla o spin-off é um ex-sócio e 
um ex-colaborador da empresa-mãe.

A sexta proposição deste trabalho trata justamente dos resultados encontrados sobre a relação entre o controle da nova empresa e o porte da empresa-mãe:

Proposição 6: Em pequenas empresas brasileiras de base tecnológica, a empresa-filha tende a ser controlada em sua totalidade pela empresa-mãe, enquanto que em médias empresas a empresa-filha tende a ter o controle compartilhado entre os ex- colaboradores, empresa-mãe e investidores.

Pfeffer e Salancik (1976) relatam que as organizações agem na direção do cumprimento de demandas de outras organizações, e que atuam gerenciando dependências que criam restrições às suas liberdades de ação. De fato, percebeuse nos casos analisados que as pequenas empresas tendem a controlar totalmente seus spin-offs corporativos. Suas empresas-filhas agem de acordo com seus interesses e demandas, conforme a perspectiva da dependência de recursos descrita anteriormente. Já nos spin-offs oriundos das empresas de médio porte, por possuírem, além da empresa-mãe, outros cotistas da empresa-filha, como investidores de risco e ex-colaboradores, a governança tende a ser compartilhada entre esses atores. Esta observações vêm novamente ao encontro do estudo de Pfeffer e Salancik (1976, p.257).

Outro aspecto analisado na pesquisa trata do acesso que empresas-filhas têm em relação aos clientes e fornecedores da empresa-mãe. Em todos os casos analisados, o acesso é irrestrito e a empresa-filha tem utilizado o histórico de mercado da empresa-mãe para obter melhores preços junto a fornecedores e atrair clientes mais rapidamente. Na Sábia Tecnologia, um dos entrevistados respondeu o seguinte quando indagado sobre este assunto: "O relacionamento com os consumidores e fornecedores da empresa-mãe são diretos, devido à forte parceria presente no ambiente do spin-off." Sendo assim, a sétima proposição deste estudo busca sintetizar a importância da variável relacionamento com clientes e fornecedores da empresa-mãe para as empresas-filhas:

Proposição 7: Empresas-filhas oriundas de processo de spin-off corporativo tendem a ter total acesso e relacionamento com clientes e fornecedores da empresa-mãe, aproveitando-se do histórico da empresa-mãe com estes atores. 
Segundo a Teoria da Visão Baseada em Recursos, toda empresa depende dos seus recursos para apresentar vantagens competitivas. Wernerfelt (1984, p. 172) define os recursos como "qualquer coisa que possa ser pensada como uma força ou fraqueza de uma dada firma". Deste modo, o objetivo de uma empresa consiste em obter ou organizar recursos que sejam superiores aos dos seus concorrentes.

A forma com que estes recursos são obtidos depende também dos atores ao redor da organização. Para as empresas-filhas nascidas por processos de spin-offs corporativos, a empresa-mãe tem a importante função de fornecer os recursos necessários para seu desenvolvimento. Ao contrário de empresas abertas por empreendedores individuais, sem o respaldo e história de uma empresa estabelecida, os spin-offs corporativos nascem já com um grande leque de contatos e utilizando-se da reputação e relacionamento da empresa-mãe com o mercado.

\subsection{Formas de captura pela empresa-mãe do valor gerado pelo spin-off}

Quanto à forma de apropriação do valor gerado pelas empresas-filhas, os quatro casos apresentaram situações distintas, porém positivas. As empresas-mãe analisadas neste trabalho reconhecem a importância para seus negócios da existência das empresas-filhas. O mesmo ocorre nas empresas filhas que têm a noção exata de sua existência dentro da cadeia de valor da empresa-mãe.

No caso 1, a geração do spin-off tem proporcionado uma maior visibilidade para a empresa-mãe, em virtude da inovação radical na qual a empresa-filha se apoia. Ao mesmo tempo, a nova empresa está recebendo maior atenção da imprensa e de potenciais investidores, o que segundo os entrevistados foi um dos motivos da realização do spin-off por parte da empresa- mãe. A afirmação a seguir foi dada por um dos entrevistados na empresa-mãe: "O valor obtido, neste caso, não é associado ao valor financeiro, mas sim ao retorno de imagem, ao marketing, que representa para nós uma estratégia".

No caso 2, a empresa-mãe está em vias de absorver os produtos e conhecimentos gerados pela empresa-filha, efetuando o processo inverso. Isto ocorre em virtude da reestruturação que a empresa-mãe está sofrendo, conforme 
um dos entrevistados: "A agregação de valor é total, porque estamos colocando para dentro da empresa-mãe de novo".

No caso 3, a empresa-mãe buscava com o spin-off diversificar seu negócio e atrair receitas de outros mercados. A empresa-filha tem firmado contratos com grandes empresas e continua desenvolvendo sua tecnologia, o que já gerou outros pedidos de patente.

Por fim, no último caso analisado, a empresa-mãe buscava completar sua cadeia de valor desenvolvendo um novo negócio que pudesse ampliar sua linha de produtos, porém para segmentos diferentes. Diante do exposto, a oitava proposição apresenta como as empresas geradoras de spin-offs podem capturar o valor gerado pelos mesmos:

Proposição 8: A captura de valor do spin-off por parte da empresa-mãe ocorre por meio de a) maior exposição da empresa-mãe em virtude da forte integração entre as duas organizações; b) incorporação de tecnologias desenvolvidas pela empresa-filha; c) parceria estratégica com a empresa-filha em segmentos estratégicos para a empresa- mãe.

O Quadro 2 a seguir apresenta um resumo dos resultados e proposições estabelecidas.

Quadro 2- Resultados e proposições estabelecidas

(continua)

\begin{tabular}{|c|c|c|}
\hline $\begin{array}{c}\text { Categorias de } \\
\text { Análise }\end{array}$ & Detalhamento & Proposições \\
\hline \multirow[t]{3}{*}{$\begin{array}{l}\text { Fatores que } \\
\text { estimularam a } \\
\text { geração dos spin-offs }\end{array}$} & $\begin{array}{l}\text { Ambiente com } \\
\text { investimento em P\&D e } \\
\text { cultura aberta ao } \\
\text { empreendedorismo } \\
\text { corporativo }\end{array}$ & $\begin{array}{l}\text { Proposição 1: Pequenas e médias empresas brasileiras } \\
\text { de base tecnológica que realizam investimentos em P\&D } \\
\text { e possuem cultura aberta ao empreendedorismo } \\
\text { corporativo são um local fértil para a geração de spin-offs } \\
\text { tecnológicos. }\end{array}$ \\
\hline & $\begin{array}{l}\text { Definição estratégica da } \\
\text { empresa-mãe }\end{array}$ & $\begin{array}{l}\text { Proposição 2: As principais motivações para a geração } \\
\text { de spin-offs corporativos tecnológicos em pequenas e } \\
\text { médias empresas brasileiras de base tecnológica são: } \\
\text { a) estratégia de diversificação da empresa-mãe; b) } \\
\text { garantia de maior foco a uma tecnologia específica que } \\
\text { dentro da empresa-mãe não seria possível; c) completar } \\
\text { a cadeia de valor da empresa-mãe. }\end{array}$ \\
\hline & $\begin{array}{l}\text { Programas } \\
\text { governamentais de apoio à } \\
\text { criação de novas } \\
\text { empresas inovadoras }\end{array}$ & $\begin{array}{l}\text { Proposição 3: Programas governamentais de apoio à } \\
\text { criação de novas empresas favorecem a geração e o } \\
\text { desenvolvimento de spin-offs por meio do capital } \\
\text { financeiro disponibilizado e consultorias especializadas } \\
\text { contratadas. }\end{array}$ \\
\hline
\end{tabular}

Revista Produção Online, Florianópolis, SC, v.14, n. 2, p. 617-647, abr./jun. 2014. 
Quadro 2- Resultados e proposições estabelecidas

(Conclusão)

\begin{tabular}{|c|c|c|}
\hline $\begin{array}{l}\text { Categorias de } \\
\text { Análise }\end{array}$ & Detalhamento & Proposições \\
\hline $\begin{array}{l}\text { Barreiras } \\
\text { encontradas }\end{array}$ & $\begin{array}{l}\text { Basicamente o acesso ao } \\
\text { capital }\end{array}$ & $\begin{array}{l}\text { Proposição 4: Nas pequenas empresas brasileiras de } \\
\text { base tecnológica, o acesso ao capital é uma barreira } \\
\text { para o desenvolvimento do spin-off em virtude deste } \\
\text { depender sensivelmente do aporte de capital pelos sócios } \\
\text { da empresa-mãe. }\end{array}$ \\
\hline \multirow[t]{3}{*}{$\begin{array}{l}\text { Estrutura } \\
\text { organizacional e } \\
\text { governança das } \\
\text { empresas-filhas }\end{array}$} & $\begin{array}{l}\text { Incubação e } \\
\text { desenvolvimento inicial da } \\
\text { ideia da criação da } \\
\text { empresa }\end{array}$ & $\begin{array}{l}\text { Proposição 5: Em pequenas e médias empresas } \\
\text { brasileiras de base tecnológica, a estreita relação entre o } \\
\text { spin-off e os interesses da empresa-mãe favorecem a } \\
\text { incubação interna do novo negócio. }\end{array}$ \\
\hline & Controle da nova empresa & $\begin{array}{l}\text { Proposição 6: Em pequenas empresas brasileiras de } \\
\text { base tecnológica, a empresa-filha tende a ser } \\
\text { controlada em sua totalidade pela empresa-mãe, } \\
\text { enquanto que em médias empresas a empresa-filha } \\
\text { tende a ter o controle compartilhado entre os ex- } \\
\text { colaboradores, empresa-mãe e investidores. }\end{array}$ \\
\hline & $\begin{array}{l}\text { Acesso a clientes e } \\
\text { fornecedores }\end{array}$ & $\begin{array}{l}\text { Proposição 7: Empresas-filhas oriundas de processo de } \\
\text { spin-off corporativo tendem a ter total acesso e } \\
\text { relacionamento com clientes e fornecedores da empresa- } \\
\text { mãe, aproveitando-se do histórico da empresa-mãe com } \\
\text { estes atores. }\end{array}$ \\
\hline $\begin{array}{l}\text { Formas de captura, } \\
\text { pela empresa-mãe, } \\
\text { do valor gerado pelo } \\
\text { spin-off }\end{array}$ & & $\begin{array}{l}\text { Proposição 8: A captura de valor do spin-off por parte da } \\
\text { empresa-mãe ocorre por meio de a) maior exposição da } \\
\text { empresa-mãe em virtude da forte integração entre as } \\
\text { duas organizações; b) incorporação de tecnologias } \\
\text { desenvolvidas pela empresa-filha; c) parceria estratégica } \\
\text { com a empresa-filha em segmentos estratégicos para } \\
\text { a empresa- mãe. }\end{array}$ \\
\hline
\end{tabular}

Fonte: Autores

Com base nos resultados que emergiram do estudo, sumarizados nas proposições estabelecidas e descritas no Quadro 2, elaborou-se um modelo esquemático, o qual encontra-se exposto na Figura 1 a seguir.

Revista Produção Online, Florianópolis, SC, v.14, n. 2, p. 617-647, abr./jun. 2014. 
Figura 1 - Processo de spin-off em pequenas e médias empresas de base tecnológica

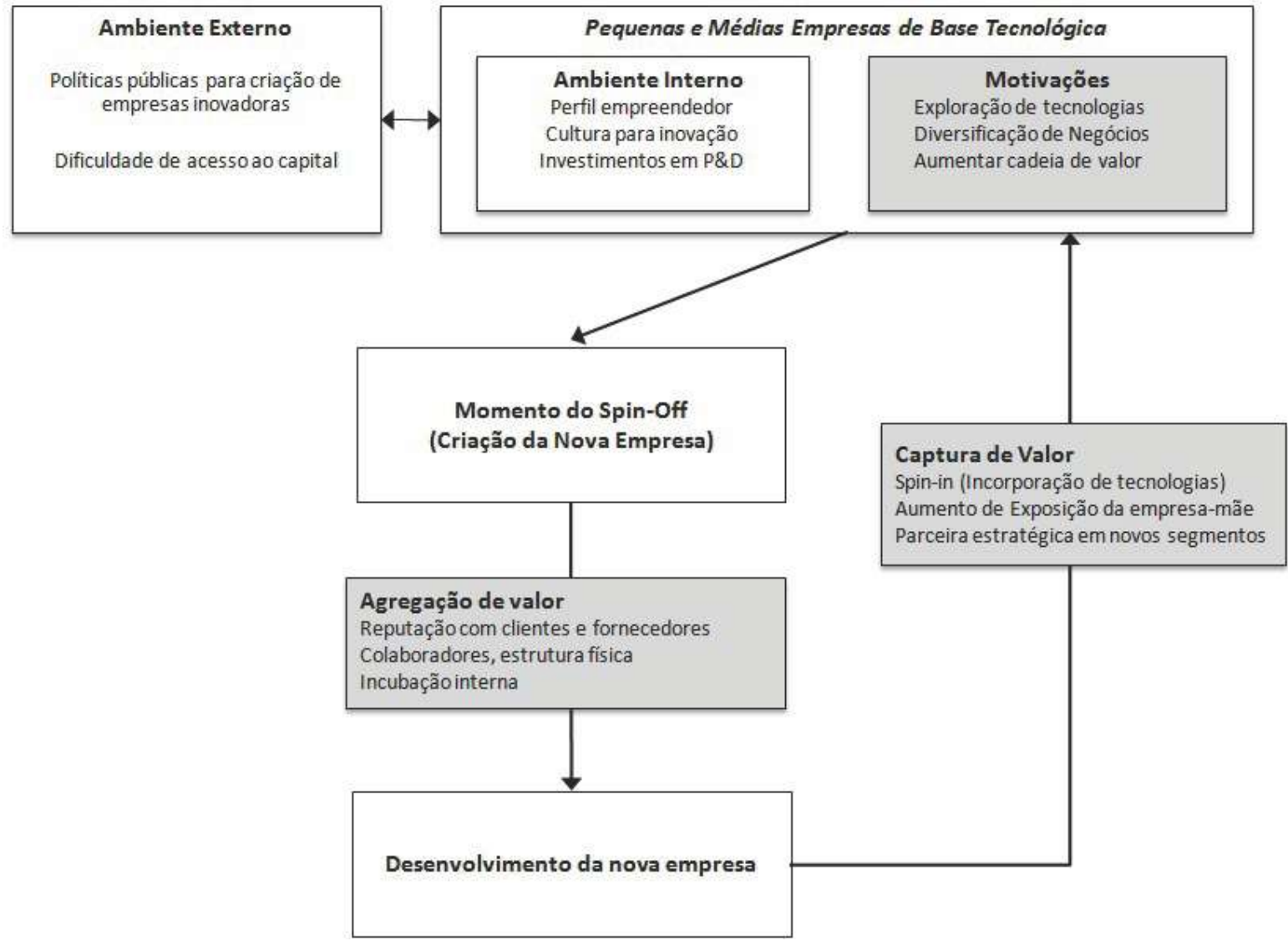

Fonte: Os autores

A Figura 1 mostra que um ambiente externo que estimule a formulação de políticas públicas de apoio à inovação, com acesso a fontes de financiamento, aliados a uma cultura interna e motivação da empresa-mãe favorável ao empreendedorismo e à inovação, acaba dando origem ao processo de spin-off. Neste processo, utiliza-se toda a estrutura desenvolvida pela empresa-mãe, tais como tecnologia, clientes e fornecedores. Como contrapartida, a empresa-filha permite, à médio prazo, que a empresa-mãe adquira conhecimento em novas tecnologias, aumentando sua expertise em áreas que possam se tornar estratégicas e importantes para seu futuro.

\section{CONCLUSÕES}

A partir da análise de quatro casos de spin-offs de cunho tecnológico ocorridos em pequenas e médias empresas brasileiras, identificaram-se os fatores motivadores para a geração deste fenômeno, as barreiras e dificuldades Revista Produção Online, Florianópolis, SC, v.14, n. 2, p. 617-647, abr./jun. 2014. 
encontradas, a agregação de valor por parte das empresas-mãe nos novos negócios, além das formas de captura, pelas empresas-mãe, do valor gerado pelos spin- offs. Os resultados encontrados levam às seguintes reflexões:

Ambiente Externo: o direcionamento de políticas públicas visando estimular a ocorrência de spin-offs favorece o nascimento de empresas mais bem nutridas, com maiores chances de sobrevivência do que as criadas por empreendedores individuais sem apoio de organizações estabelecidas. As iniciativas e programas governamentais de apoio financeiro à criação de novas empresas, como o programa PRIME da FINEP, favorecem a geração e o desenvolvimento de spin-offs. Todos os entrevistados foram unânimes em argumentar que a dificuldade em obter financiamento para abertura de novos negócios é a principal barreira para a geração de spin-offs tecnológicos nas pequenas e médias empresas. Tais resultados estão alinhados aos fatores encontrados na revisão da literatura (LUC E FILLION, 2002), discutidos no item 2.2.1 deste trabalho.

Ambiente Interno: investimentos em P\&D e cultura organizacional aberta ao empreendedorismo contribuem para a geração de spin-offs nas pequenas e médias empresas de base tecnológica. Todas as empresas analisadas possuíam em sua cultura a chama da inovação, com investimentos visando à invenção de novas tecnologias, modelos de negócios e produtos inovadores. Este ambiente atinge tanto os sócios quanto os colaboradores destas empresas, que se sentem motivados a empreender. Apesar do fenômeno spin-off de cunho tecnológico estar mais relacionado às grandes corporações com seus investimentos maciços em pesquisa e desenvolvimento, identificou-se por meio desta pesquisa que as pequenas e médias empresas constituem-se também um ambiente propício para o surgimento e desenvolvimento deste processo.

Motivação: as principais motivações encontradas para a geração de spinoffs corporativos em pequenas e médias empresas de base tecnológica foram: a) estratégia de diversificação da empresa-mãe; b) garantia de maior foco a uma tecnologia específica que dentro da empresa-mãe não seria possível e c) completar a cadeia de valor da empresa-mãe. Christensen (1997) encontrou que uma das principais motivações para a geração de spin-offs seria o desenvolvimento de tecnologias disruptivas. Talvez pelo fato deste estudo concentrar-se em 
empresas menores, as motivações encontradas estavam mais ligadas às estratégias de diversificação ou tecnologias específicas que completam a cadeia de valor da empresa-mãe e não tanto a tecnologias disruptivas.

Momento do spin-off, agregação de valor e desenvolvimento do novo negócio: esta pesquisa indica que quanto menor o porte da empresa geradora do spin-off, maior será a relação entre esta e a nova empresa. A estreita relação entre o spin-off e os interesses da empresa-mãe favorece a incubação interna do novo negócio. Em todos os casos analisados, a interdependência entre a nova empresa e a empresa-mãe, principalmente em seus primeiros anos, foi muito forte. A empresa-filha alimentava-se dos recursos (capital financeiro, capital humano e capital social) da empresa-mãe para desenvolver-se e sobreviver. Diante deste cenário, as empresas-mãe optavam por incubar o novo negócio em suas instalações até que o mesmo estivesse pronto para lançar-se no mercado. Tais resultados estão alinhados com os resultados obtidos por Teece (1998), o qual aponta a importância do novo negócio receber forte patrocínio da empresa-mãe.

Ao final do trabalho, acredita-se que o mesmo tenha atingido seu objetivo, que é o de compreender como pequenas e médias empresas podem inovar por meio de spin-offs tecnológicos. O estudo revelou que uma cultura interna forte voltada ao empreendedorismo e à inovação, em conjunto com políticas públicas que incentivem a inovação empresarial, incluindo aí a questão do financiamento, encoraja o processo de spin-off tecnológico. Neste processo, o apoio da empresa-mãe, no sentido de oferecer sua rede de clientes, fornecedores e tecnologia é fundamental para o sucesso da iniciativa.

Como sugestão de trabalhos futuros está a avaliação de casos ocorridos em outros contextos dentro do território brasileiro, bem como em outros setores da economia, como farmacêutico, automotivo, entre outros. A comparação entre os casos de spin-offs ocorridos a partir de pequenas e médias empresas com os casos oriundos de grandes empresas também é um estudo necessário para revelar a influência do porte das empresas-mãe neste processo. 


\section{REFERÊNCIAS}

ANDRADE JR., P. P. (2012). Análise por agrupamento de fatores de desempenho de empresas de base tecnológica em incubadoras: estudo das incubadoras do Estado de Santa Catarina. Revista Produção Online, Florianópolis, v. 12, n. 1, p. 205-228. http://dx.doi.org/10.14488/1676-1901.v12i1.868

ANSLINGER, P. et al. Equity carve-outs: a new spin on the corporate structure. The McKinsey Quarterly, 1, p. $165-172,1997$.

BARDIN, L. Análise de conteúdo. 5. ed. Portugal: Edições 70, 2010.

BHIDÉ, A.V. The origin and evolution of new businesses. New York: Oxford University Press, 2000.

BIRKINSHAW, J. Entrepreneurship in multinational corporations: the characteristics of subsidiary initiatives. Strategic Management Journal, 18, p. 207-229, 1997. http://dx.doi.org/10.1002/(SICl)1097-0266(199703)18:3<207::AIDSMJ864>3.0.CO;2-Q

BOTELHO, A.J.J. E ALMEIDA, M. Overcoming institutional shortcomings for academic spin-off policies in Brazil. International Journal of Technology Management \& Sustainable Development, v. 9, n. 3, p. 175-193, 2010. http://dx.doi.org/10.1386/tmsd.9.3.175 1

BRAY, M. J.; LEE, J. N. University revenues from technology transfer: licensing fees vs. equity positions. Journal of Business Venturing, v.15, p. 385-392, 2000. http://dx.doi.org/10.1016/S0883-9026(98)00034-2

BRUNO, F.S.; NETTO, H.F.; NETTO, A.C.M. (2011). Aspectos impulsionadores do potencial inovador da indústria têxtil e de confecção no distrito criativo de Flandres: inspirações para a formulação de políticas no Brasil. Revista Produção Online, Florianópolis, v. 11, n. 4, p. 1028-1058. http://dx.doi.org/10.14488/16761901.v11i4.713

BURGELMAN, R. A. A process model of internal corporate venturing in the diversified major firm. Administrative Science Quarterly, 28, p. 223-244, 1983. http://dx.doi.org/10.2307/2392619

CARAYANNIS, E. G. et al. High technology spin-offs from government R\&D laboratories and research institutes. Technovation, v. 18, n. 1, p. 1-10, 1998. http://dx.doi.org/10.1016/S0166-4972(97)00101-6

CHESBROUGH, H. Open innovation: the new imperative for creating and profiting from technology. Harvard Business School Press, Boston, Mass, 2003. 
CHESBROUGH, H.; ROSENBLOOM, R.S. The role of the business model in capturing value from innovation: evidence from xerox corporation's technology spinoff companies. Industrial and Corporate Change, v. 11, n. 3, p. 529-555, 2002. http://dx.doi.org/10.1093/icc/11.3.529

CHRISTENSEN, C.\& RAYNOR, M. The innovator's solution: creating and sustaining successful growth. Harvard Business School Press, 2003.

CHRISTENSEN, C. The innovator's dilemma. Harvard Business School Press, Boston, Mass, 1997.

COOPER, A. C. Spin-offs and technical entrepreneurship. IEEE Transactions on Engineering Management, v. 18, n. 1, 2-6, 1971.

http://dx.doi.org/10.1109/TEM.1971.6447118

COSTA, L.B.; TORKOMIAN, A.L. Um estudo exploratório sobre um novo tipo de empreendimento: os spin-offs acadêmicos. RAC - Revista de Administração Contemporânea, v. 12, n. 2, p. 395-427, 2008.

DAHLSTRAND, A. L Entrepreneurial spin-off enterprises in Göteborg, Sweden. European Planning Studies, v. 5, n. 5, p. 659-673, 1997q. http://dx.doi.org/10.1080/09654319708720424

DAHLSTRAND, A. L. Growth and inventiveness in technology-based spin-off firms. Research Policy, 26, 331-344, 1197b. http://dx.doi.org/10.1016/S0048-7333(97)00016-4

DORNELAS, J.C.A. Empreendedorismo corporativo. 1. ed. Rio de Janeiro: Campus, 2003.

DRUCKER, P.F. Inovação e espírito empreendedor : entrepreneurship. 6. ed. São Paulo: Pioneira, 1985.

Eisenhardt, K.M. Building theories from case study research. Academy of Management Review, v.14, n.4, 532-550, 1989.

http://dx.doi.org/10.5465/AMR.1989.4308385

http://dx.doi.org/10.2307/258557

FREEMAN, C. The economics of industrial innovation. London: Frances Pinter, 1982.

GARVIN, D. Spin-offs and the new firm formation process. California Management Review, v. 15, n. 2, p. 3-20, 1983.

http://dx.doi.org/10.2307/41165001

GIL, A.C. Como elaborar projetos de pesquisa. 4. ed. São Paulo: Atlas, 2002. 
GODOY, A. S. Introdução à pesquisa qualitativa e suas possibilidades. Revista de Administração de Empresas, v. 35, n. 2, p. 57-63, 1995.

http://dx.doi.org/10.1590/S0034-75901995000200008

GUTH, W.D. \& GINSBERG, A. Guest's editors introductions. Strategic

Management Journal. Edição Especial: Corporate Entrepreneurship, v. 2, p.5-15, 1990

HELLMANN, T. When do employees become entrepreneurs? Stanford University Working Paper, v. 53, n. 6, p. 919-933, 2007.

KANTER, R.M. When giants learn to dance. New York: Simon \& Schuster, 1989.

LA ROVERE, R. L. Perspectivas das micro, pequenas e médias empresas no Brasil. Revista de Economia Contemporânea. Rio de Janeiro. v. 5. Edição Especial, 2001.

LAZZARI, F.; BAMPI, R. E.; MILAN, G. S. Os esforços de inovação e sua relação com alguns indicadores de desempenho do negócio. Revista Produção Online, v. 14, n.1, 2014. http://dx.doi.org/10.14488/1676-1901.v14.i1.1428

LIMA, M. A. M.; MENDES, J. P. F. Inovação na gestão organizacional e tecnológica: conceitos, evolução histórica e implicações para as micro, pequenas e médias empresas no Brasil. Revista Produção Online, v. 3, n. 2, 2003.

http://dx.doi.org/10.14488/1676-1901.v3i2.622

LOWE, J. Commercialization of university research: a policy perspective.

Technology Analysis and Strategic Management, v. 5, n.1, p. 27-37, 1993.

http://dx.doi.org/10.1080/09537329308524115

LUC, D.; FILION, L. J. Rapport de recherche. essaimage d'entreprises

classiques. 1998-2001. Cahier de Recherche 2002-11, Montreal, École des Hautes Études Commerciales, 2002.

MONCADA-PATERNÒ-CASTELLO, P. ET AL. The Impact of Corporate Spin-offs on Competitiveness and Employment in the European Union. Institute for Prospective Technological Studies (IPTS), TechnicaReport. 1999. Disponível em: <http://www.jrc.es/pages/projects/corporate/welcome.html>.

MIZIARA, G.; CARVALHO, M.M. Fatores críticos de sucesso em incubadoras de empresas de software. Revista Produção Online, Florianópolis, v. 8, n.3, p. 1-10, 2008. http://dx.doi.org/10.14488/1676-1901.v8i3.131

MUEGGE, S. Corporate ventured technology spin-offs: a grounded theory of decision and resource environments. department of systems and computer engineering, carleton university, 2004. Disponível em:

<http://www.carleton.ca/ callahan/muegge2004.pdf>.

Revista Produção Online, Florianópolis, SC, v.14, n. 2, p. 617-647, abr./jun. 2014. 
NELSON, R. R.; WINTER, S. G. An evolutionary theory of economic change. Estados Unidos: Harvard U. P. 1982.

O'CONNOR, G. C.; DEMARTINO, R. Organizing for radical innovation: an exploratory study of the structural aspects of ri management systems in large established firms. Journal of Product Innovation Management, 23: 475-497, 2006. http://dx.doi.org/10.1111/j.1540-5885.2006.00219.x

ORGANIZAÇÃO PARA A COOPERAÇÃO ECONÔMICA E DESENVOLVIMENTO (OECD) . Manual de Oslo: diretrizes para a coleta e interpretação de dados sobre inovação, 2005. Disponível em:

<http://www.finep.gov.br/imprensa/sala_imprensa/manual_de_oslo.pdf>.

PARHANKANGAS, A. \& ARENIUS, P. From a corporate venture to an independent company: a base for a taxonomy for corporate spin-off firms. Research Policy, v.32, n.3, p. 463-481, 2003. http://dx.doi.org/10.1016/S0048-7333(02)00018-5

PETERS, T. \& WATERMAN, R. In search of excellence: lessons from america's best run companies. New York: Harper and Row, 1982.

PFEFFER, J., \& SALANCIK, G. R. The effect of uncertainty on the use of social influence in organizational decision making. Administrative Science Quarterly, v. 21, n. 2, p. 227-245, 1976. http://dx.doi.org/10.2307/2392044

PINCHOT III, G. Intrapreneuring: por que você não precisa deixar a empresa para tornar-se um empreendedor. São Paulo: Habra, 1985.

PIRNAY, F.; SURLEMONT, B.; NLEMVO, F. Towards a typoloy of university spinoffs. Small Business Economics, v. 21, n. 4, p. 355- 369, 2003.

http://dx.doi.org/10.1023/A:1026167105153

RICHARDS, S. Inside business incubators and corporate ventures. New York: John Wiley and Sons, 2001.

ROBERTS, E. B.; MALONE D. Policies and structures for spinning off new companies from research and development organization. R\&D Management, v. 26, n. 1, 17-48, 1996. http://dx.doi.org/10.1111/j.1467-9310.1996.tb00927.x

Selltiz, C.et al. Métodos de pesquisa nas relações sociais. 5 ed. São Paulo, Editora da Universidade de São Paulo, 1975.

SEMADENI, M.; CANNELLA JR., A.A. Examining the performance effects of post spin-off links to parent firms: should the apron strings be cut? Strategic Management Journal, v. 32, p. 1083-1098, 2011.

http://dx.doi.org/10.1002/smj.928 
SHANE, S. Academic entrepreneurship: university spinoffs and wealth creation. Cheltenham: Edward Elgar, 2004.

http://dx.doi.org/10.4337/9781843769828

SHARMA, P. \& CHRISMAN, J. Toward a Reconciliation of the Definitional Issues in the Field of Corporate Entrepreneurship. Entrepreneurship Theory and Practice, V. 23, n. 3, p. 11-27, 1999.

TEECE, D. Economic performance and the theory of the firm. Cheltenham: Edward Elgar Publishing Inc, 1998.

TÜBKE, A. Success factors of corporate spin-offs. New York: Springer Science+Business Media, 2004.

Wernerfelt, B. A resource-based view of the firm. Strategic Management Journal, Hoboken, 5, 171-180, 1984. http://dx.doi.org/10.1002/smj.4250050207

VON HIPPEL, E. The sources of innovation. Oxford University Press, 1988.

Yin, R. The case study crisis: some answers. Administrative Science Quarterly, v. 26, p. 58-65, 1981. http://dx.doi.org/10.2307/2392599

YIN, R. Estudo de caso: planejamento e método. 2 ed. Porto Alegre: Bookman, 2001.

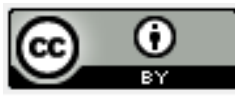

Artigo recebido em 02/09/2012 e aceito para publicação em 23/04/2014. DOI: http://dx.doi.org/10.14488/1676-1901.v14i2.1436 